\title{
Microscopy101
}

\section{Making Your Own Hair Probe: A Letter to the Editor}

\section{Gayle M. Callis}

GCallis Histology Service, LLC, 1442 Ash Drive, Bozeman, MT 59715

gayle.callis@bresnan.net

To the Editor:

I read with great interest the Microscopy 101 article, "Making Your Own Hair Probe: A Simple Guide" [Bob Chiovetti, Microscopy Today 22(6) (2014) 46]. We made hair probes for TEM in the early 1960s using human eye lashes mounted with pink dental wax onto shortened applicator sticks. A word of caution was given about using eyelashes coated with mascara. We were told mascara can flake off and cause contaminates, that is, "floaters," which could end up on sections and grids. Photos of a mascara-coated eyelash and an uncoated eyelash have been donated by Phil Oshel (Figure 1). My compliments to Bob Chiovetti for providing excellent details on how to make hair probes. This brought back fond memories of working in an EM laboratory so many years ago.

Respectfully yours,

Gayle M. Callis HTL/HT/MT (ASCP)
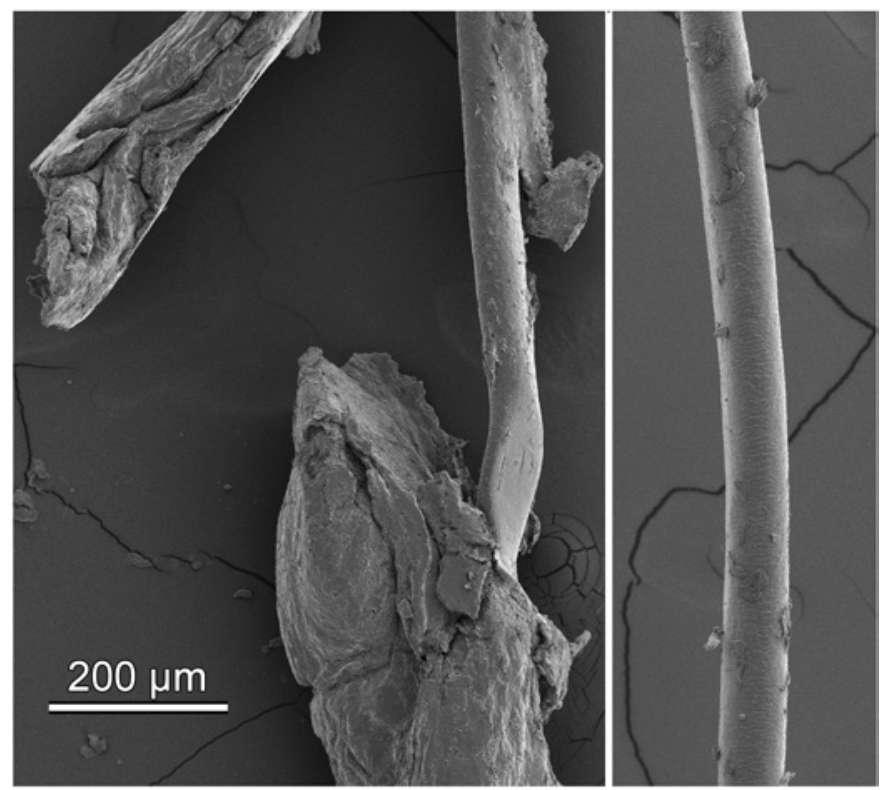

Figure 1: Eyelashes from the same person. Left, with mascara, and right, a clean eyelash.

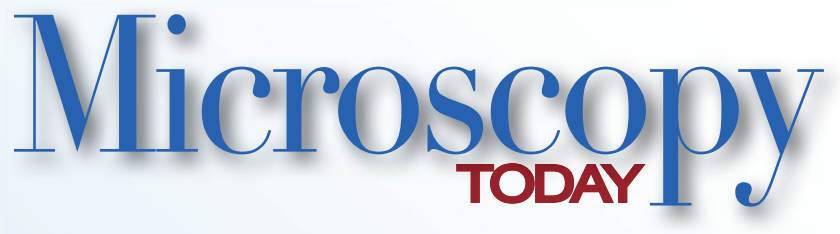

\section{Innovation Awards}

Congratulations to the winners of the 2015 awards:

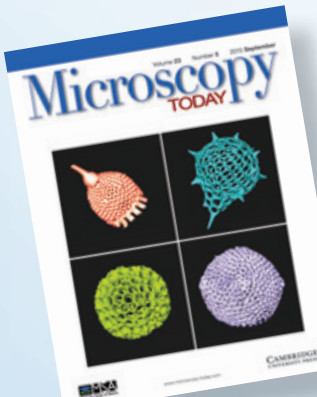

- Daylight Solutions, Inc.

- E.A. Fischione Instruments, Inc.

- Gatan, Inc.

- Klocke Nanotechnik GmbH

- National Institute of Standards and Technology

- Nanolive SA

- Nanonics Imaging, Ltd.

- Aydogan Ozcan of UCLA

- Phenom-World BV

- Carl Zeiss Microscopy GmbH

Next entry deadline: March 21, 2016 Application forms at www.microscopy-today.com 